psoriatic arthritis (PsA). However, these findings are mainly based on materials from an era of less active treatment of the IJD's and thus progress in this theory may have happened. Further, many cases fail to fulfil any classification criteria. We found no published data on CV risk in unspecified arthritis (UA).

Objectives: To investigate the association between the five most common IJDs and CHD based on a nationwide large register data in Finland during 2000-14. Methods: From the register maintained by the Social Insurance Institution (SII), we collected data on all Finnish patients granted a new special reimbursement (SR) on medications for the following IJDs during 2000-14: seropositive RA (ICD10 code M05), seronegative RA (M06), UA (M13), spondyloarthritis (SpA) (M45-46), and PsA (L40). For these patients, Population Register Centre matched three controls, standardized for age, sex, and place of residence. The index date was determined to be the date when the SR for IJD came effective. From the case and control groups we analysed the frequency of individuals that had SR also for CHD (ICD10 codes I20-25) at the index date, or to whom it was granted by SII during the observation period.

Results: Altogether 201776 individuals (50 444 cases and 151332 controls) were identified. The frequencies of the individuals having CHD by the index date and the incidences of CHD during follow-up are presented in table 1.

Conclusions: Compared to general population, CHD was overrepresented at RA diagnosis, especially in seropositive men and seronegative women, while other patients had comparable rates of $\mathrm{CHD}$ with the population. After the index day, the incidence of CHD was increased in all patient groups except for men with seronegative RA and women with seropositive RA or SpA. Thus, the CV risk associated to IJDs remains in this millennium, and also pertains to UA.

Disclosure of Interest: None declared

DOI: 10.1136/annrheumdis-2017-eular.2027

\section{THU0164 SUBCLINICAL ATHEROSCLEROSIS AND CARDIOVASCULAR EVENTS IN ITALIAN PATIENTS WITH RHEUMATOID ARTHRITIS: RESULTS FROM MULTICENTER GIRRCS (GRUPPO ITALIANO DI RICERCA IN REUMATOLOGIA CLINICA E SPERIMENTALE) STUDY}

P. Ruscitti ${ }^{1}$, D.P.E. Margiotta ${ }^{2}$, L. Navarini ${ }^{2}$, F. Macaluso ${ }^{3}$, D. lacono ${ }^{4}$ F. D'Onofrio ${ }^{5}$, G. Emmi ${ }^{6}$, F. Atzeni ${ }^{7}$, M. Prete ${ }^{8}$, F. Perosa ${ }^{8}$, P. Sarzi-Puttini ${ }^{7}$, L. Emmi ${ }^{6}$, F.P. Cantatore ${ }^{5}$, G. Triolo ${ }^{3}$, R. Giacomelli ${ }^{1}$, G. Valentini ${ }^{4}$

${ }^{1}$ Rheumatology Section, Department of Biotechnological and Applied Clinical Science, University of L'Aquila, L'Aquila; ${ }^{2}$ Clinical Medicine and Rheumatology Department, Campus Bio-Medico University of Rome, Rome; ${ }^{3}$ Rheumatology Section, Department of Internal Medicine, University of Palermo, Palermo; ${ }^{4}$ Rheumatology Section, Department of Clinical and Experimental Medicine, Second University of Naples, Naples; ${ }^{5}$ Rheumatology Section, Department of Medical and Surgical Sciences, University of Foggia Medical School, Foggia; ${ }^{6}$ Department of Experimental and Clinical Medicine, University of Florence, Florence, ${ }^{7}$ Rheumatology Section, L. Sacco University Hospital, Milan; ${ }^{8}$ Systemic Rheumatic and Autoimmune Diseases Unit, Department of Biomedical Sciences and Human Oncology, University of Bari Medical School, Bari, Italy

Background: Several studies showed a close relationship between Rheumatoid Arthritis (RA) and accelerated atherosclerosis $[1,2]$. At the best of our knowledge, no such study has been carried out in a large Italian series.

Objectives: To investigate the prevalence of presence of subclinical atherosclerosis and history of cardio-cerebrovascular events (CVEs), in 1266 patients consecutively admitted to Rheumatology Units throughout the whole Italy.

Methods: From 01/01/2015 to 31/12/2015, 1266 consecutive patients admitted to GIRRCS centres, satisfying ACR/EULAR criteria for RA were investigated for: i. traditional cardiovascular risk factors: gender, age, smoking habit, cholesterol, triglycerides, glycemia, systemic arterial hypertension (SAH), metabolic syndrome (MS), type 2 diabetes (T2D); ii. RA aspects: disease duration as assessed from the first symptom, disease activity as evaluated by DAS28, radiographic damage by joint X-ray, and joint surgery; iii. subclinical atherosclerosis, as assessed by ultrasound technique and/or atherosclerotic peripheral lesions; iv. history of CVEs. Results: We evaluated 1176 patients out of 1266, that were investigated for both CVEs and subclinical atherosclerosis. They were mostly females $(80.52 \%)$, with a median age of 60 years (range 18-91 years), a median disease duration of 12 years (range $0.8-25$ years), seropositive in $69.21 \%$. Nineteen percent were in remission; $17.51 \%$ presented low disease activity; $39.45 \%$ moderate disease activity, $22.61 \%$ high disease activity.

Out of 1176 patients, $217(18 \%)$ showed evidence of subclinical atherosclerosis: a figure lower than that reported worldwide (32.7\%) [2]. Eighty-two patients (6.9\%) had a history for CVEs (58 myocardial infarction, 38 heart failure, 10 ischemic transitory attack, 7 Stroke), too this figure is lower than that reported worldwide $(8.5 \%)[3,4]$. In multivariate analysis, older age $(p=0.0001$, OR:1.069, Cl95\%:1.05-1.09), MS ( $\mathrm{p}=0.0001$, OR:3.417, Cl95\%:2.16-5.40) and SAH ( $p=0.0001$, OR:3.714, Cl95\%:2.23-6.17) and high disease activity $(p=0.001$, OR:2.117, CI95\%:1.35-3.32) were significantly associated with the presence of subclinical atherosclerosis. Male gender $(\mathrm{p}=0.0001$, OR:3.465, C195\%:1.946.185), MS ( $\mathrm{p}=0.005$, OR:2.542, Cl95\%:1.29-4.52), T2D ( $\mathrm{p}=0.007$, OR:2.324, Cl95\%:1.29-4.29) and SAH ( $\mathrm{p}=0.001$, OR:4.921, Cl95\%:2.14-11.45) and higher disease activity $(\mathrm{p}=0.003$, OR:1.316, Cl95\%:1.15-1.68) were significantly associated with a history of CVEs.

Conclusions: This is the first Italian multicenter study on subclinical and clinical atherosclerosis in patients with RA. We pointed out a low prevalence of both subclinical atherosclerosis and history of CV events. Nonetheless, a high disease activity and presence of cardiovascular risk factors were found to play a role, similarly to other countries.

References:

[1] Ruscitti P, et al. PLoS One. 2017;12:e0170108.

[2] Ambrosino P, et al. Thromb Haemost. 2015;113:916-30.

[3] Solomon D et al. Ann Rheum Dis. 2010;69:1920-5.

[4] Avina-Zubieta JA, et al. Ann Rheum Dis. 2012;71:1524-9.

Disclosure of Interest: None declared

DOI: 10.1136/annrheumdis-2017-eular.4733

\section{THU0165 RISK OF HERPES ZOSTER IN PATIENTS WITH RHEUMATOID ARTHRITIS IN THE BIOLOGICS ERA BASED ON THE IORRA COHORT}

R. Yamaguchi ${ }^{1}$, A. Nakajima ${ }^{1}$, E. Inoue ${ }^{2}$, M. Ochiai ${ }^{1}$, Y. Shimizu ${ }^{1}$, N. Sugimoto ${ }^{1}$, E. Tanaka ${ }^{1}, \mathrm{~K}$ Ikari $^{1}$, A. Taniguchi ${ }^{1}$, H. Yamanaka ${ }^{1} .{ }^{1}$ Institute of Rheumatology, Tokyo Women's Medical University, Tokyo, Japan, ${ }^{2}$ National Center for Child Health and Development, Center for Clinical Research for Development, Tokyo, Japan

Background: A high incidence of herpes zoster $(\mathrm{HZ})$ in patients with rheumatoid arthritis (RA) has been reported (1). According to our previous report on the incidence of $\mathrm{HZ}$ in Japanese patients with RA enrolled in the IORRA (Institute of Rheumatology, Rheumatoid Arthritis) cohort from 2005 to 2010, the standardized incidence rate (SIR) of $\mathrm{HZ}$ per 1,000 patient-years was 9.1 (95\% confidence intervals [95\% Cls]: $6.2-12.9$ ) (2). In that study, $3.0 \%$ of patients used biologics at baseline. Subsequently, the use of biologics has increased, and many new potent disease-modifying antirheumatic drugs (DMARDs) have been introduced. The treatment strategy for RA has progressed in recent years; thus, it is important to investigate whether there is a change in the $\mathrm{HZ}$ incidence rate and the risk factors for $\mathrm{HZ}$ with the expanded use of biologics.

Objectives: To elucidate the incidence of $H Z$ and risk factors for $H Z$ in $R A$ patients in the IORRA cohort.

Methods: The IORRA cohort is a large, single institute-based, observational cohort of RA patients established at the Institute of Rheumatology, Tokyo Women's Medical University, in 2000. Among patients with RA enrolled in the IORRA surveys from 2010 to 2015, the incidence of $\mathrm{HZ}$ was extracted based on patients' self-report and confirmed by the medical records. The SIR with $95 \%$ Cls was calculated and risk factors for $\mathrm{HZ}$ were analyzed using a Cox regression analysis.

Results: For 7,815 patients with RA (female, $84.7 \%$ ) who were analyzed, the median [interquartile range (IQR)] age was 61.0 [49.7-68.9] years, and disease duration was 10 [4-18] years. Baseline drugs (median dose [IQR]) included prednisolone (PSL, 4 [2-5] mg/day) in 36.8\%, methotrexate (MTX, 8 [6-10] $\mathrm{mg} /$ week) in $70.4 \%$, and biologics in $14.7 \%$ of patients. Among 7,815 patients with 25,863 patient-years of observation (male, 3,828; female, 22,035), $340 \mathrm{HZ}$ events were confirmed in 309 patients (21 patients had multiple events). The SIR per 1,000 patient-years was 8.5 (95\% Cl: 6.9-10.5) in total, 6.0 (95\% Cl: 3.7-9.2) in males, and $11.0(95 \% \mathrm{Cl}: 8.7-13.7)$ in females. The following hazard ratios $(\mathrm{HR})$ were found: unit increase of age, $1.14(95 \% \mathrm{Cl}: 1.03-1.26, p<0.05)$; J-HAQ score $0.5-1.5$ (reference J-HAQ score $=0$ ), $1.51(95 \% \mathrm{Cl}$ : 1.09-2.10, $\mathrm{p}<0.05)$; MTX use, $1.58(95 \% \mathrm{Cl}: 1.06-2.36, p<0.05)$; and biologics use, $1.88(95 \% \mathrm{Cl}$ : $1.44-2.47, \mathrm{p}<0.01$ ). PSL use was not a risk factor (PSL dose $<5 \mathrm{mg} /$ day: $\mathrm{HR}$ 1.17 [95\% Cl: $0.91-1.51, p=0.22]$; PSL dose $\geqq 5 \mathrm{mg} /$ day: HR 1.17 [95\% Cl: $0.72-1.91, \mathrm{p}=0.52]$; the reference PSL dose $=0 \mathrm{mg} /$ day).

Conclusions: The drugs that were a risk factor for $\mathrm{HZ}$ were PSL and MTX in our previous study when the use of biologics was not prevalent. In this study, the drugs that were a risk factor for HZ were MTX and biologics, but not PSL in the era when the use of biologics became frequent.

References:

[1] Wolfe $\mathrm{F}$ et al. Rheumatology (Oxford). 2006;45:1370

[2] Nakajima A et al. Mod Rheumatol 2015;25:558.

Disclosure of Interest: R. Yamaguchi: None declared, A. Nakajima Consultant for: Bristol-Meyers, Mitsubishi Tanabe Pharma, Nippon Kayaku Co. Ltd., Novartis Pharma, Pfizer, Siemens Healthcare Diagnostics K.K. and Takeda Pharmaceutical Company., Speakers bureau: Bristol-Meyers, Mitsubishi Tanabe Pharma, Nippon Kayaku Co. Ltd., Novartis Pharma, Pfizer, Siemens Healthcare Diagnostics K.K. and Takeda Pharmaceutical Company., E. Inoue: None declared, M. Ochiai: None declared, Y. Shimizu: None declared, N. Sugimoto Speakers bureau: Takeda Pharmaceutical and Bristol Myers Squibb., E. Tanaka Consultant for: Abbvie, Eisai Pharmaceutical, Chugai Pharmaceutical, Bristol Myers Squibb, Astellas Pharmaceutical, Pfizer, Takeda Pharmaceutical, and Ayumi Pharmaceutical., K. Ikari Grant/research support from: Astellas, UCB, Bristol-Meyers, Pfizer, Eisai, Tanabe-Mitsubishi, Chugai, AbbVie, Janssen Pharmaceutical, Otsuka, Kaken, Asahi-Kasei, Hisamitsu and Takeda., Speakers bureau: Astellas, UCB, Bristol-Meyers, Pfizer, Eisai, Tanabe-Mitsubishi, Chugai, AbbVie, Janssen Pharmaceutical, Otsuka, Kaken, Asahi-Kasei, Hisamitsu and Takeda., A. Taniguchi Grant/research support from: AbbVie, Eisai, Takeda, Tanabe-Mitsubishi, Teijin Pharma, Pfizer., Speakers bureau: AbbVie, Eisai, Takeda, Tanabe-Mitsubishi, Teijin Pharma, Pfizer., H. Yamanaka Grant/research support from: MSD, Ayumi, AbbVie, Eisai, Ono, Astellas, Daiichi-Sankyo, Taisyo-Toyama, Takeda, Tanabe- 
Mitsubishi, Chugai, Teijin Pharma, Torii, Nippon Shinyaku, Pfizer. UCB. Nippon Kayaku, YL biologics, Bayer and Bristol-Meyers., Consultant for: MSD, Ayumi, AbbVie, Eisai, Ono, Astellas, Daiichi-Sankyo, Taisyo-Toyama, Takeda, TanabeMitsubishi, Chugai, Teijin Pharma, Torii, Nippon Shinyaku, Pfizer. UCB. Nippon Kayaku, YL biologics, Bayer and Bristol-Meyers., Speakers bureau: MSD, Ayumi, AbbVie, Eisai, Ono, Astellas, Daiichi-Sankyo, Taisyo-Toyama, Takeda, TanabeMitsubishi, Chugai, Teijin Pharma, Torii, Nippon Shinyaku, Pfizer. UCB. Nippon Kayaku, YL biologics, Bayer and Bristol-Meyers.

DOI: 10.1136/annrheumdis-2017-eular.3046

\section{THU0166 COMPARISON OF THE RISK OF COMORBIDITIES BETWEEN PATIENTS WITH RHEUMATOID ARTHRITIS AND DIABETES MELLITUS USING JAPANESE HEALTH INSURANCE DATABASE}

R. Sakai ${ }^{1}$, S. Kasai ${ }^{2}$, M. Tsutsumino ${ }^{1}$, H. Yamanaka ${ }^{1}$, N. Miyasaka ${ }^{3}$ M. Harigai ${ }^{1} .{ }^{1}$ Division of Epidemiology and Pharmacoepidemiology in Rheumatic Diseases, Institute of Rheumatology, Tokyo Women's Medical University; ${ }^{2}$ Department of Rheumatology, Graduate School of Medical and Dental Sciences, Tokyo Medical and Dental University; ${ }^{3}$ Tokyo Medical and Dental University, Tokyo, Japan

Background: Patients with rheumatoid arthritis (RA) have a higher risk of comorbidities such as infections ${ }^{1}$, cardiovascular diseases ${ }^{2}$, and fractures ${ }^{3}$ than general population. To understand the risk of these comorbidities in RA more precisely, it is needed to compare the risk between RA and other chronic diseases. A Dutch study ${ }^{4}$ showed that patients with RA had comparable risk of cardiovascular diseases to diabetes mellitus (DM). Because of possible racial or ethnic difference of risks of comorbidities, it is warranted to compare the risk between RA and DM in Asian countries.

Objectives: To compare risk of hospitalized infections (HIs), cardiovascular diseases and stroke (CVDs), and fractures between RA and DM cases using Japanese health insurance database.

Methods: This retrospective longitudinal population-based study was conducted using claims data provided by the Japan Medical Data Center Co., Ltd. We defined individuals as RA cases if they met all of the following: 1) had at least 6 months of continuous enrollment in the health insurance database; 2) had at least one RA diagnostic code and at least one prescription of disease-modifying antirheumatic drugs between January 2005 and December 2013; and 3) were $\geq 50$ years old (RA group, $n=3,607$ ). Among individuals who met above criteria 1) and had at least DM diagnostic code and at least one prescription of drugs for DM, but did not meet 2), we selected age- ( \pm 5 years), gender-, calendar year of the observation start, and observation length-matched DM cases at 1:3 ratio (RA: DM) (DM group, $n=10,821$ ). Each comorbidity was defined as follows: HIs, at least one ICD10 code and one prescription of drugs for infections with hospitalization; CVDs, at least one ICD10 code and one prescription of drugs or medical procedures for CVDs with hospitalization; fractures, at least one ICD10 code for fractures. We calculated incidence rates (IR) with $95 \%$ confidence interval (CI) of each comorbidity in the two groups up to 10 years and adjusted odds ratio (OR) of RA compared with DM for each comorbidity using generalized estimating equation.

Results: The median age was 58 , and $75.1 \%$ were female in the both groups. The IR [95\% Cl] of HIs, CVDs, and fractures was 2.8 [2.5-3.2]/100 patient years (PY), 9.2 [7.4-11.4]/1,000 PY, $16.7[14.2-19.6] / 1,000$ PY in the RA group, $2.8[2.6-$ 3.0]/100PY, $26.3[24.4-28.3] / 1,000 \mathrm{PY}, 10.3[9.1-11.6] / 1,000 \mathrm{PY}$ in the DM group respectively. The OR [ $95 \% \mathrm{Cl}$ ] of RA (vs. DM) for HIs, CVDs, fractures was 0.9 [0.8-1.1], 0.4 [0.3-0.6], 1.3 [1.0-1.7] after adjusting for baseline characteristics. Conclusions: This study revealed that patients with RA had significantly lower risk of CVDs than and similar risk of Hls and fractures to those with DM using health insurance database for the first time in Asia.

\section{References:}

[1] Arthritis Rheum, 2002;46:2287-93.

[2] Ann Rheum Dis, 2012:71:1524-29.

[3] Arthritis Res Ther, 2010;12:R154.

[4] Arthritis Rheum, 2009;61:1571-9.

Acknowledgements: This work was supported by the research grant from the Ministry of Health, Labour, and Welfare, Japan.

Disclosure of Interest: R. Sakai Grant/research support from: Ayumi Pharmaceutical Co., Chugai Pharmaceutical Co., Ltd., Eisai Co., Ltd., Nippon Kayaku Co., Ltd., Taisho Toyama Pharmaceutical Co., Ltd., Takeda Pharmaceutical Co., Ltd., Mitsubishi Tanabe Pharma Co., and Teijin Pharma Ltd.,Bristol-Meyers Squibb, S. Kasai: None declared, M. Tsutsumino Grant/research support from: Ayumi Pharmaceutical Co., Chugai Pharmaceutical Co., Ltd., Eisai Co., Ltd., Nippon Kayaku Co., Ltd., Taisho Toyama Pharmaceutical Co., Ltd., Takeda Pharmaceutical Co., Ltd., Mitsubishi Tanabe Pharma Co., and Teijin Pharma Ltd., H. Yamanaka Grant/research support from: Chugai Pharmaceutical Co. Ltd., Astellas Pharma Inc., Bristol-Meyers Squibb, AbbVie Japan Co. Ltd., Daiichi-Sankyo, Mitsubishi-Tanabe Pharma Corp., Takeda Pharmaceutical Co. Ltd., UCB Japan., Consultant for: Chugai Pharmaceutical Co. Ltd., Astellas, Bristol-Meyers Squibb, AbbVie Japan Co. Ltd., Daiichi-Sankyo, Mitsubishi-Tanabe Pharma Corp., Takeda Pharmaceutical Co. Ltd., UCB Japan., Speakers bureau: Chugai Pharmaceutical Co. Ltd., Astellas, Bristol-Meyers Squibb, AbbVie Japan Co. Ltd., Daiichi-Sankyo, Mitsubishi-Tanabe Pharma Corp., Takeda Pharmaceutical Co. Ltd., UCB Japan.,
N. Miyasaka: None declared, M. Harigai Grant/research support from: Ayumi Pharmaceutical Co., Chugai Pharmaceutical Co., Ltd., Eisai Co., Ltd., Nippon Kayaku Co., Ltd., Taisho Toyama Pharmaceutical Co., Ltd., Takeda Pharmaceutical Co., Ltd., Mitsubishi Tanabe Pharma Co., and Teijin Pharma Ltd.,Eisai,

DOI: 10.1136/annrheumdis-2017-eular.4558

\section{THU0167 ASSOCIATION OF BIOLOGIC ANTIRHEUMATIC THERAPY WITH THE RISK OF DEVELOPING TYPE 2 DIABETES IN ADULTS WITH RHEUMATOID ARTHRITIS: NEW EVIDENCE FROM REAL WORLD DATA}

S.K. Paul ${ }^{1}$, O. Montvida ${ }^{2}$, J.H. Best ${ }^{3}$, S. Gale ${ }^{3}$, A. Pethoe-Schramm ${ }^{4}$ K. Sarsour ${ }^{3}$. ${ }^{1}$ University of Melbourne, Melbourne; ${ }^{2}$ QIMR Berghofer Medical Research Institute, Brisbane, Australia: ${ }^{3}$ Genentech, South San Francisco, CA, United States; ${ }^{4}$ F. Hoffmann-La Roche, Basel, Switzerland

Background: While rheumatoid arthritis (RA) has been associated with the increased risk of developing type 2 diabetes mellitus (T2DM), few basic science studies have indicated the possible beneficial role of some biologic diseasemodifying antirheumatic drugs (bDMARDs), including the interleukin-6 (IL-6) based DMARDs, on insulin resistance in patients with RA.

Objectives: To evaluate the impact of treatment with bDMARDs, including the IL-6 inhibitors, on the probability of developing T2DM in a real world setting. Methods: From the Centricity Electronic Medical Records of GE Healthcare, a longitudinal cohort of 192,509 US adults (age $\geq 18$ years) with diagnosis of RA from January 2000 to April 2016 was selected. Patients were excluded if they had a prior history of diabetes, cancer and micro- or macro-vascular diseases at diagnosis of RA. Four mutually exclusive antirheumatic treatment groups (TGs) were identified by diagnosis date (Dx) and treatment initiation date (ID): tocilizumab (TCZ, $n=843$ ), TCZ+Other bDMARDs (TCZ+obDMARD, $n=2489$ ), non-TCZ other bDMARDs (obDMARD, $n=45,262)$ and no bDMARD $(n=143,915)$. Within the treatment groups, 142,225 patients had a minimum 6 months of exposure before development of T2DM or end of follow-up. Treatment-effects regression models were used to estimate the probabilities $(95 \% \mathrm{Cl})$ of developing T2DM during follow-up in the 4 TGs after adjusting and balancing with inverseprobability-weighted regression for various factors including age, sex, smoking status, body mass index, use of non-biologic DMARDs, use of statins, anaemia status and follow-up time post ID.

Results: At diagnosis, the 142,225 patients were on average 55 years old, $22 \%$ male, $71 \%$ white Caucasian, $13 \%$ with anaemia, and $32 \%$ obese with mean BMl of $29 \mathrm{~kg} / \mathrm{m}^{2}$. About $28 \% / 42 \%$ were using statins $/ \mathrm{MTX}$ at diagnosis or during follow-up before development of T2DM. During mean 4.6 years of follow-up from Dx, 2.6\%/2.6\%/5.3\%/5.8\% developed T2DM in the TCZ/TCZ+obDMARD/obDMARD/no bDMARD TGs. The adjusted probability of developing T2DM was 0.05 (95\% Cl: 0.04, 0.05) in no bDMARD group; with significantly lower probability of developing T2DM in TCZ [0.02 (95\% Cl: 0.01 , 0.04)], TCZ+obDMARD [0.03 (95\% Cl: $0.02,0.04)]$ and obDMARD [0.01 $(95 \%$ Cl: 0.01, 0.02)] groups (Table). Hypertension, higher BMI and Statin use were associated with significantly higher probability of developing T2DM by 0.25 (95\% Cl: $0.16,0.35), 0.08$ (95\% Cl: $0.07,0.08$ ) and 0.36 (95\% Cl: $0.27,0.47)$ respectively. Patients with anaemia had $8 \%$ higher likelihood of developing T2DM $(\mathrm{p}=0.13)$. Among those who received any $\mathrm{DDMARD}$, those who ever received TCZ had significantly lower probability of developing T2DM $(0.024,95 \% \mathrm{Cl}: 0.02$, $0.03)$, compared to those who were never exposed to TCZ therapy.

Table: The probability of developing T2DM, adjusted by age, sex, BMI, anaemia; balanced on hypertension, follow-up, obDMARDs and statin usage.

\begin{tabular}{|c|c|c|}
\hline & Probability $(95 \% \mathrm{CI})$ & Difference $(95 \% \mathrm{CI})$ \\
\hline No bDMARD & $0.046(0.045,0.048)$ & - \\
\hline obDMARD Only & $0.041(0.039,0.044)$ & $-0.005(-0.008,-0.002)$ \\
\hline TCZ Only & $0.025(0.006,0.043)$ & $-0.022(-0.04,-0.003)$ \\
\hline TCZ+obDMARD & $0.018(0.01,0.026)$ & $-0.029(-0.037,-0.02)$ \\
\hline \multicolumn{3}{|c|}{ Among those who received any bDMARDs } \\
\hline No TCZ & $0.046(0.044,0.049)$ & - \\
\hline TCZ & $0.023(0.017,0.029)$ & $-0.024(-0.03,-0.017)$ \\
\hline
\end{tabular}

Conclusions: This study indicates the possible beneficial role of IL-6 inhibitors (TCZ) in reducing the likelihood of developing T2DM among adults without major co-morbidities at diagnosis of RA.

Acknowledgements: Funding by F. Hoffmann-La Roche/Genentech.

Disclosure of Interest: S. Paul Grant/research support from: Therapeutic Innovations Australia, O. Montvida: None declared, J. Best Employee of: Genentech, S. Gale Employee of: Genentech, A. Pethoe-Schramm Employee of: F. Hoffmann-La Roche, K. Sarsour Employee of: Genentech DOI: 10.1136/annrheumdis-2017-eular.5222 